\title{
Exploring Psychosocial Experiences of Parents with Children Undergoing Cancer Treatment at Korle-Bu Teaching Hospital
}

\author{
Sheena Adu-Assiamah \\ Ghana College of Nurses and Midwives, Accra, Ghana \\ Email: sheenza3@gmail.com
}

How to cite this paper: Adu-Assiamah, S. (2022) Exploring Psychosocial Experiences of Parents with Children Undergoing Cancer Treatment at Korle-Bu Teaching Hospital. Open Access Library Journal, 9: e8429. https://doi.org/10.4236/oalib.1108429

Received: February 7, 2022

Accepted: February 25, 2022

Published: February 28, 2022

Copyright $\odot 2022$ by author(s) and Open Access Library Inc.

This work is licensed under the Creative Commons Attribution International License (CC BY 4.0).

http://creativecommons.org/licenses/by/4.0/ (c) (i) Open Access

\begin{abstract}
Background: Parental support is integral in the care of paediatric patients. Cancer treatment creates diverse challenges and parents adopt various coping skills to overcome the stress of the period. Aim: To explore the psychosocial experiences of parents at the Paediatric Oncology Unit of Korle-Bu Teaching Hospital. Methods: An explorative qualitative study was conducted using interviews and participants observations. Eleven parents whose children are undergoing cancer treatment at the paediatric oncology unit of Korle Bu Teaching Hospital were recruited for the study. Data analysis and discussion werediscussions were guided by the Caregiving Process and Caregivers' Burden framework. Findings and Relevance to Clinical Practice: The results from the study indicated that parents were severely affected by psychosocial challenges on account of their child's treatment. Major challenges identified include financial constraints, unemployment, over reliance of extended family members to care for other children, distress and family disintegration. Parental support groups should be formed in the POU to facilitate parent's adjustment and coping during the treatment period. Conclusion: children undergoing cancer treat at Korle-Bu Teaching Hospital and their parents need lots of psychological and socioeconomic support as they go through this trying and uncertain period. Limitation and Recommendations for Further Research: These findings are applicable to parents at KBTH from both urban, peri-urban and rural context. Further research with parents in various oncology units across Ghana would be useful to expand on the research findings and would potentially assist in programmes development. Understanding the Ghanaian situation can improve practices and services rendered to these families.
\end{abstract}

\section{Subject Areas}

Nursing 


\section{Keywords}

Psychosocial Stress, Cancer, Parents Coping, Caregiver, Social Support

\section{Introduction}

A child's cancer diagnoses put the parents in a long journey of doubt, prolonged hospital care and constant emotional stress. Childhood cancer diagnosis presents challenges to parents, family members and/or significant others and health workers, alike [1]. Parents have to play an expanded role by reconciling parental task and treatment demands. In addition, the complex treatment modalities can be over whelming, disrupting livelihood activities and family function [1]-[7].

Childhood cancer is the second leading cause of death in children aged one to fourteen and increasing globally, with the highest incidence in developing countries [8] [9] [10] [11]. In Ghana, about 16,000 cases of cancer occur annually with 1000 cases recorded among children. The age range of children diagnosed with cancer at the Korle-Bu Teaching Hospital (KBTH) extended from six weeks to twelve years [11] [12].

Parents' efficient involvement in the care and management of a child with cancer is dependent on the ability of parents to effectively cope and manage the distress associated with the diagnosis, treatment of the child and its consequences [13] [14] [15]. To survive these trying periods, parents develop various coping strategies, such as, involving in religious activities, developing friendship with other parents whose children are equally diagnosed with cancer and affiliating with social support groups [7] [16] [17].

A Ghanaian study on the experiences of parents caring for children with cancer found only negative experiences including financial burden, loss of job, stigma from the public and fear of death [4] [12] [18]. Most journals reviewed highlight the negative experience of parents with little input on positive knowledge gained and how these have helped parents. Just as the health needs of children with cancer are essential, so must the parent be in an optimum state of health to play his or her role well. The parent must have good quality of life, to be able to provide similar care to the child with the condition. Gaining knowledge into the positive experiences of parents can inform how other parents can be assisted when their children are diagnosed with cancer. Given the inadequate literature on the parental psychosocial experience of childhood cancer treatment in Ghana, this study was conducted to explore the psychosocial experiences of parents whose children are undergoing cancer treatment at the Paediatric Oncology Unit.

\section{Methods}

\subsection{Study Design, Sample Size and Sampling Technique}

Qualitative research design, using explorative, descriptive approach was conducted 
among 11 parents of children (less than 13 years) undergoing cancer treatment at KBTH in Accra-Ghana. Purposive sampling was used to select parents who lived and cared for children receiving treatment for various cancer conditions. They were interviewed until data saturation was obtained at a sample size of 11 parents.

\subsection{Data Collection Procedure}

Data was collected between April and May 2019. A one-on-one in-depth interview was granted using a semi structured interview guide. Data was gathered in Twi and English through audio recording and field notes. The recoded data were transcribed verbatim to English from Twi. Back translation was conducted to ensure the meaning of the data was not lost in translation.

\subsection{Data Processing and Analysis}

The audio recordings were transcribed into Microsoft Office Word document version 13 then imported into NVIVO software version 10 for coding and analyzed using thematic analysis. Codes were developed based on identified key concepts. Trustworthiness was established based on participants' response from the interview, inquiry audit by done by the STC.

\subsection{Ethical Considerations}

Ethical clearance was sought from the Scientific and Technical Committee and Institutional Review Board of KBTH. Informed consent was sought from every participant prior to recruitment. The relevant ethical principles applied to research was also be adhered to.

Data sharing statement: data gather in the study are kept confidential. The final study published in peer review journal.

\section{Results}

\subsection{Parent's Socio-Demographic Characteristics}

All participants $(\mathrm{n}=11,100 \%)$ were females and biological parents of the children. Majority of the participants $(n=7,63.6 \%)$ were separated from their spouses, and ( $\mathrm{n}=4,36.4 \%)$ were married. Out of those separated 4 was on account of the child's illness whiles 3 were separated before the child's illness. Most participants $(n=9,81.8 \%)$ were Christians and the remaining $(n=2,18.2)$ Muslims.

\subsection{Children's Demographic Characteristics}

The age range of the children was between 2 - 13 years. Majority $(n=4,36.3 \%)$ of the children were in their early adolescence stage (10 - 13 years). All the children had had frequent hospitalization in the past with an average of three admissions in a month. 


\subsection{Emerging Themes}

The narrative of the parents revealed varying positive and negative experiences whiles caring for the children diagnosed with cancer. For each concept, both negative and positive experienced are outlined in Table 1.

\subsection{Theme One: Family Caregivers' Socio-Economic Experiences}

\subsubsection{Negative Experiences}

1) Financial constraints

The cost of cancer treatment was mentioned by all participants as great challenge. It became evident that payment for treatment of their child's care was a grave burden that parent cannot bear. Most of the parents use up all their saving earnestly in the initial quest for curing their child. This zeal, however, decreases as they run out of funds. One parent said: "When coming I had some money down. I had planned to build my own house. I had all of that money on me. I did as I was directed until it got finished. The health insurance was also helpful" (POU009).

Parental financial challenges transcend into the ability of the parent to provide food, clothing, school item and other resources for the index child and other

Table 1. Emerging themes from interview with participants.

\begin{tabular}{|c|c|c|c|c|c|c|c|c|c|c|c|}
\hline Themes & 1 & 2 & 3 & 4 & 5 & 6 & 7 & 8 & 9 & 10 & 11 \\
\hline \multirow{4}{*}{$\begin{array}{l}\text { Family Caregivers' Socio-Economic Experiences } \\
\text { - Financial constraints } \\
\text { - Extended family and friends support } \\
\text { - Marital disintegration } \\
\text { - Insurance status }\end{array}$} & $\mathrm{X}$ & $X$ & $\mathrm{X}$ & $\mathrm{X}$ & X & $X$ & $X$ & \multirow[t]{3}{*}{$\mathrm{X}$} & \multirow[t]{3}{*}{$\mathrm{X}$} & $\mathrm{X}$ & $\mathrm{X}$ \\
\hline & $\mathrm{X}$ & $\mathrm{X}$ & $\mathrm{X}$ & $\mathrm{X}$ & $\mathrm{X}$ & $\mathrm{X}$ & $\mathrm{X}$ & & & $\mathrm{X}$ & $\mathrm{X}$ \\
\hline & $\mathrm{X}$ & $\mathrm{X}$ & & & & & $\mathrm{X}$ & & & & $\mathrm{X}$ \\
\hline & $\mathrm{X}$ & $\mathrm{X}$ & $\mathrm{X}$ & $\mathrm{X}$ & $\mathrm{X}$ & $\mathrm{X}$ & $\mathrm{X}$ & $\mathrm{X}$ & $\mathrm{X}$ & & $\mathrm{X}$ \\
\hline \multirow{7}{*}{$\begin{array}{l}\text { Family Caregivers Stress Experi } \\
\text { - Anxiety about child's future } \\
\text { - } \quad \text { Altered sleep pattern } \\
\text { - Increased knowledge } \\
\text { - } \quad \text { Care giving demands } \\
\text { - Stigma } \\
\text { - Fear } \\
\text { - } \quad \text { Negative changes in lifestyle }\end{array}$} & $\mathrm{X}$ & $\mathrm{X}$ & $\mathrm{X}$ & $\mathrm{X}$ & $\mathrm{X}$ & $\mathrm{X}$ & $\mathrm{X}$ & $\mathrm{X}$ & $\mathrm{X}$ & $\mathrm{X}$ & $\mathrm{X}$ \\
\hline & $\mathrm{X}$ & $\mathrm{X}$ & $\mathrm{X}$ & $\mathrm{X}$ & $\mathrm{X}$ & $\mathrm{X}$ & $\mathrm{X}$ & $\mathrm{X}$ & $\mathrm{X}$ & $\mathrm{X}$ & $\mathrm{X}$ \\
\hline & $\mathrm{X}$ & $\mathrm{X}$ & $\mathrm{X}$ & $\mathrm{X}$ & $\mathrm{X}$ & $\mathrm{X}$ & $\mathrm{X}$ & $\mathrm{X}$ & $\mathrm{X}$ & $\mathrm{X}$ & $\mathrm{X}$ \\
\hline & $\mathrm{X}$ & $\mathrm{X}$ & $\mathrm{X}$ & $\mathrm{X}$ & $\mathrm{X}$ & $\mathrm{X}$ & $\mathrm{X}$ & $\mathrm{X}$ & $\mathrm{X}$ & $\mathrm{X}$ & $\mathrm{X}$ \\
\hline & & & $\mathrm{X}$ & $\mathrm{X}$ & & $\mathrm{X}$ & $\mathrm{X}$ & & $\mathrm{X}$ & $\mathrm{X}$ & $\mathrm{X}$ \\
\hline & $\mathrm{X}$ & $\mathrm{X}$ & $\mathrm{X}$ & $\mathrm{X}$ & $\mathrm{X}$ & $\mathrm{X}$ & $\mathrm{X}$ & $\mathrm{X}$ & $\mathrm{X}$ & $\mathrm{X}$ & $\mathrm{X}$ \\
\hline & $\mathrm{X}$ & $\mathrm{X}$ & $\mathrm{X}$ & $\mathrm{X}$ & $\mathrm{X}$ & $\mathrm{X}$ & $\mathrm{X}$ & $\mathrm{X}$ & $\mathrm{X}$ & $\mathrm{X}$ & $\mathrm{X}$ \\
\hline \multirow{4}{*}{$\begin{array}{l}\text { Family Caregivers Coping/Support Experience } \\
\text { - Spiritual experience: increased belief in God } \\
\text { - } \quad \text { Religious support } \\
\text { - Social support } \\
\text { - Supportive staff }\end{array}$} & $\mathrm{X}$ & $\mathrm{X}$ & $\mathrm{X}$ & $\mathrm{X}$ & $\mathrm{X}$ & $\mathrm{X}$ & $\mathrm{X}$ & $\mathrm{X}$ & $\mathrm{X}$ & \multirow[t]{2}{*}{$\mathrm{X}$} & \multirow[t]{2}{*}{$\mathrm{X}$} \\
\hline & & & & $\mathrm{X}$ & $\mathrm{X}$ & $\mathrm{X}$ & $\mathrm{X}$ & $\mathrm{X}$ & $\mathrm{X}$ & & \\
\hline & $\mathrm{X}$ & $\mathrm{X}$ & $\mathrm{X}$ & $\mathrm{X}$ & $\mathrm{X}$ & $\mathrm{X}$ & $\mathrm{X}$ & $\mathrm{X}$ & $\mathrm{X}$ & $\mathrm{X}$ & $\mathrm{X}$ \\
\hline & $\mathrm{X}$ & $\mathrm{X}$ & $\mathrm{X}$ & $\mathrm{X}$ & $\mathrm{X}$ & $\mathrm{X}$ & $\mathrm{X}$ & $\mathrm{X}$ & $\mathrm{X}$ & $\mathrm{X}$ & $\mathrm{X}$ \\
\hline
\end{tabular}

Key: X-patient experience. 
siblings. "Her feeding is different. They gave me a book for feeding her but I can't afford. I give her some of whatever I get” said a parent (POU011). “... That's the issue. We leave on the help of others. I can't afford food and clothing for my other children because of his treatment" said another (POU009).

The availability of the NHIS to all persons save parents from some treatment cost. This however, does not cover for chemotherapy, surgeries and other vital scans. One parent experienced how treatment cost would be like without NHIS and said: "We were uninsured with NHIS initially; sometime when they write medicine for me to go and buy, it becomes very difficult. I take the prescription around begging for money. I put shyness aside stand at the entrance of Korle Bu main gate begging strangers for money" (POU010).

Out of pocket is the only mode of payment that parents can use to meet the expense of chemotherapy, diagnostic tests such as computerized tomography scan and pathology treatment due to its high cost. All the participants had their children registered with the NHIS and this they all said this does not do much though it covers of some of their labs and non-cancer drugs. "The chemo and some treatment are not covered by the insurance; what it covers is the FBC but for most it doesn't cover" (POU002).

The prolonged hospital stay and duration of treatment impact the employment status of the parents. Some parent said: "The child's illness has affected me in so many ways. For instance, I can't work... I can't work. Staying here, he can take injections for a week or ten day. Just when we are about to be discharged then he falls sick again. In the period of 1 year, 8 months we have gone home 3 times and that was not even to say" said another (POU009).

2) Marital disintegration

Paediatric cancer treatment has great effect on marital relations. It could lead to stronger family bound or complete disintegration of the family unit. The presence of spouse helps with the care of the sibling, provision of money and other resources to cater for the sick child. There is an avenue for communication and emotional support from one's spouse; this is however, lost when the one caring for the child is a single parent. Some of the married participants said: "I have no support person at home. It's only my husband who help financially" (POU004).

Single parents had different view. One said: "We had a good relationship when the child was healthy. In the initial stages of the illness, he used to help from time to time. When it got to the stage, we were transferred to Korle- $\mathrm{Bu}$, he said the child's illness was not 'hospital illness' (implying the illness has a spiritual connotation and the professional healthcare providers are unable to treat diseases of spiritual origin) so we should go and see an herbalist or medicine man. Because of that he doesn't communicate to us anymore" (POU002).

\subsubsection{Positive Experience}

1) Extended family and friend support

For many families, cancer diagnosis is experienced as a traumatic event. The importance of friends and extended family in providing support and some assis- 
tance were mentioned by all participants. All parents made reference to how their challenges would have aggravated had they lost this support. Family members and relations are very helpful in the beginning but as the day go by their support and assistance also decreases. One mother said: "I do have financial challenges. Since my side of the family has decided to support, initially the support was there but now it has decreased greatly; really decreased. At least everyone one has their small family that they are caring for so financially it is not easy" (POU001).

This great support system declines overtime as interaction with friend and family also decline. All participants attested to a decline to complete non-existence of some friendship due to their child's ill. Parents are unable to attend social functions and family programs. These are exemplified in the following quotes: “... we eventually turned this place into our home. All the things I enjoyed doing I have stopped going out, stopped attending programmes. They told us he can't go in the mist of people. We are always indoors" (POU010).

\subsection{Theme Two: Family Caregivers' Stressful Experience}

\subsubsection{Negative Experiences}

1) Anxiety about child's future

All parents verbalised they constantly think about their sick child's wellbeing as well as that of the other children (siblings of the index child). Their thoughts revolve around feeding, how to get money, treatment outcome of the child and how their other children are faring. Some stated: "I think about it a lot. I ask myself what if after all this money we have spent he doesn't survive" (POU004); "I just stay in my room and thing about it. I ask God if I have done something wrong" (POU010).

2) Care giving demands

All parents interviewed were directly involved in the care of their sick child. They took this decision based on the sympathy they have towards the child. Alongside their usual parenting duties (washing, brushing, cooking, etc.), they outlined the following as actions undertaken when caring for their child: "I teach her. She doesn't go to school. When I came here, I was told she shouldn't go to school because of the treatment. So I try to teach her myself at home" (POU001), "in the ward, I bath him in the morning then he brushes his teeth. I am the one who sends him to the lab. He is too young for this especially when we go for bone marrow aspiration, it really feel for him" (POU002).

3) Altered sleep pattern

All participants reported altered sleeping pattern due prolonged stay in the hospital and the increasing caring demands of the child. This impacts their ability to support the child adequately and performed ordered instructions from health workers. “At night I can't sleep. I am just thinking. Because of that I don't sleep. I was always seated in the chair for I month 2 weeks that we spent here (Oncology ward). I am always thinking where am I going to get help?" (POU011).

4) Stigma 
There were diverse views on the issue of stigma. Parents reported being cautious of allowing their children to go out or play with other children. These they stated were precautions instituted by the hospital to prevent infection. One parent stated she has not experienced any stigma however the rest gave account on how people reacted when they saw their children especially during the critical stages of their illness. The diverse stigma related experiences are as narrated: "He became very skinny. He was all bones. Even going to kitchen to heat food, people at the hostel will be starring, even you (indicating the principal investigator) will stare" (POU003). "Mummy why don't I have hair. When I go to school my friends laugh at me calling me santobele (a local term for baldness)" (POU004).

5) Fear

Paediatric cancers are reportedly curable, regardless, parents still face great fear at the outcome of their child's illness. Communication gabs, lack of information and observation of other children illness outcomes heightens this fear. Some parents narrated: "I really do fear because at times when I look at some of the children, some passing out but still, I am on my feet. I am really afraid that she will leave. Though I am really involved, I asked myself if this disease will go, will she really get better, will there be a time she won't take chemo again? Will she be able to go to school and do the normal things that other children do? Sometimes these things scare me, and I think about them. But I am looking to God" (POU001).

6) Negative changes in lifestyle

The responsibilities associated with the care giving demands for the child leads to altered lifestyle of the parent. Such changes in behaviour include starving in order to get food for the child, decreased sleep, excessive thinking and loss of interest to participate in social events. "I am not fine but what can I do? At times I eat once. Life is not easy. This life is not easy. At times it cause me drink. I am becoming alcoholic. I am always sad. I have no joy" (POU11).

\subsubsection{Positive Experiences}

1) Increased knowledge

All parents were aware of the side effects of chemotherapy on their children. They acknowledged that health workers provide them with information and instruct them on what to do should the child experience any, before presenting to the hospital. They also inform them of danger signs to report immediately to the hospital. Some comments include: "I usually give him para (paracetamol) for high body temperature. He really suffers when he takes the chemo (chemotherapy). He can vomit continuously like a pregnant woman. He may not eat for three days to a week. They told me that can happen. I usually give him fruits until he is okay to eat again" (POU009).

\subsection{Theme Three: Family Caregivers' Coping/Support Experience} Positive Experiences

1) Spiritual/religious support 
More than half of the parents cope through religious support. This is unsurprising as all participants belonged to a religious body. Religion, spirituality or life philosophy help parents make sense of their child's situation. "My pastor organised some youth in the church to donate blood for my son. If not that we would have paid more than 1000 Cedis for the blood" (POU010). Some were member of religious bodies but had never received any assistance from them. "I told my church about the child's illness. They asked I bring a letter for us to take round for contribution. Till date. Anytime I ask the pastor he says he has not received anything" (POU007).

The quest for cure and the ability of parents to understand the situation of their children take them to various healing source before finally seeking orthodox treatment. All the parents reported that they had first consulted traditional healers before seeking medical intervention in the hospital, due to the traditional belief systems that they practiced; "My father recommended an herbalist for me whom I sent him (child) to. He (the herbalist) encouraged I sent the child to a hospital" (POU002). Most of the participants had hope of cure for their children. They believed that their child will recover and go home. Their trust was in God to heal the children. They said: "Oh my son will be well. I have faith that he will be well. Plenty people have left and more keeps coming but we have faith the he will be well" (POU002).

2) Social support

All participants had sponsorship from individuals, NGO or support groups. The sponsorship is solely to cover for the child's treatment. These sponsorships had decreased the financial burden of cancer treatment for the parents. They stated: "I pay for his everything myself. But it is now that I seem to have found some help here. I have a sponsor now" (POU010).

3) Supportive staff

Health workers relationships was reported as the bedrock of patients and parents support. Their interactions with the parents help them acquire in-depth knowledge into their child's condition. They reported that health workers are one of their support and they depend on them to cope: "It hasn't been easy. The nurses and doctors have been really nice. There were times I almost gave up but they encourage me" (POU005).

\section{Discussion}

\subsection{Parent's Socio-Demographic Characteristics}

The findings of this study showed that participated in the study were mostly youthful females with eight of them aged between 20 - 40 years. All participants were the biological parents of the children and are with the child constantly either during treatment or at home except when the child had to go to school. This finding is similar to other family care giver studies and this supports the fact that women turn to bear the social responsibility of caring for children. This is particularly so in the African traditional systems where women are expected to main- 
tain the household and raise children [19]. Christianity was identified as the religion of overwhelming majority of participants.

\subsection{Children's Demographic Characteristics}

The children whose parents participated in the study were aged between two to thirteen years. The children were diagnosed with Leukemias, Wilms Tumour, Retinoblastomas, Hodgkin and Non-Hodgkin Lymphomas. This is in support of a South African study that identified that in Ghana, lymphomas, Central Nervous System tumours, Nephroblastomas, Leukemia and Hepatic tumours were the five most reported cases among paediatric patient [20]. All the children in the study had to quit school for some time due to the treatment or their general condition. Those who had completed their treatment or were awaiting the next phase of treatment and were stable had returned to school. This is consistent with Brand and colleagues study that identified that a child' cancer diagnose and treatment interrupt regular school routines. Most children are able to continue with their education full time when they complete treatment [21]. All the children have had frequent hospital visits in the past. Averagely a child is admitted to the hospital about three times in a month. The frequency of hospitalization increases when the child is acutely ill. The duration of stay in the ward varies ranging from weeks to months. This supports [22] who assess 1197 children in their research titled impact of chronic health conditions on the length of stay and mortality in general PICU. They concluded in the study that increased durations in admission is associated with chronic illness in children [22].

\subsection{Family Caregivers' Socio-Economic Experiences}

The findings from the study identified family socio-economic experiences to be in line with financial constraints, extended family and friends support and marital disintegration. The finding revealed participants have more negative socio-economic experience as compared to positive ones.

All parents in the study mentioned financial constraint as a huge burden. Financial constraints strongly influenced their health seeking behaviours as this determines if they can bring the child to the hospital and afford the prescribed treatment. Financial challenges aggravate parents' stress. While some families remain resilient, others disintegrate at the overwhelming role they perform alongside financial challenges [2]. The parents felt hampered by the financial commitment they have toward their child's treatment and this is worsen by their lack of employment and nonexistence of constant income. This current unemployment status was attributed to prolong hospital stay, frequent hospital visits and increasing care giving demands of the child. This challenge transcend into the capability of these parents to provide food, clothing, school items and other resources for the sick child and other siblings. 2 of parents were employed in corporate organizations and could provide for their children with minimal challenges. Some parents starve or ate leftovers from their children food in order to 
save some money to provide the best they can for their children. They neglect their own health focusing solely on that of the child. In all these, lone parents seem to fair worse compared to married parents. This pattern of parental financial situation, though similar to the situation in other studies from resource limited countries [6] [23], is in contrast to a Swedish study where married and single parents had similar financial strengths and could care for their child with lesser financial stress [1].

Due to the tremendous psychosocial role they play in the lives of parent/sick child, the importance of extended family and friends during such difficult periods cannot be overlooked. In this study, though parents reported losing old friends during the initial treatment stages, they also gained new ones who seem to be more understanding toward the day to day struggles of the dyads of the parents and their sick child. Regardless, parents however felt rejected by people whom they thought they could rely on during such difficult periods. According to Clarke and colleagues [24], cancer friends turn to be more understanding to the pain and worries of the family as they are considered to really know what the child is experiencing hence it is easily to discuss ones emotions honestly and openly [23]. Family support was cited by nine participants. Family members and relation are very helpful in the treatment of child's cancer but as the days goes by their support and assistance declined. The parents understood that extended family support could not be eternal and greatly appreciated the support they gained from them. These supports came in the form of encouragement, caring for other children in the absence of their parent as well as financial assistance. Two parents had no extended family support and seem to have more heightened psychosocial challenged as compared to parents who had family assistance. These parents seem to have lost trust and hope of support from other people, as they were of the view their own families had abandoned them.

The availability of the NHIS to all person save parents from some treatment cost. This however does not cover for chemotherapy, surgeries and other vital scans. Though NHIS does not do much it seems a better option than not possessing one. Its absence can increase treatment cost that overwhelms parents. Paying for treatment directly without any subsidy becomes the only option parents can use to afford their child's treatment. In this study, all the participants had their children registered with the NHIS and this they all said this does not do much but cover some of their laboratory investigations and non-cancer drugs. This is consistent with another Ghanaian study by Renner and colleagues [10]. The authors also concluded that, although the NHIS is available for patient treatment and cure, it does not cover chemotherapy and diagnostic tests such as computerized tomography scan and pathology treatment due to its high cost [10].

One of the key findings that emerged, was the effect that paediatric cancer treatment had on marital relationships of the participants. Four of the participants were married before the child's diagnosis and were still married to their 
spouses. These participants had financial support, emotional support as well as caring for the child and siblings as some benefit derived from their spouses. They are able to discuss the child's treatments with someone who is equally concerned by the child's illness and they do not feel alone in this hard period. Four other parents had separated from their marriage on account of their child's illness. These separation evolved from disagreement over treatment options, spouse blame, influences from in-laws and extended family members and the belief that the illness was of spiritual origin thus cannot be cured in the hospital. The marital status of parents being greatly affected by a child's diagnosis has some links with other studies which noted that diagnosing cancer in children could lead to stronger family bound or complete disintegration of the family unit. Strain in marital relationship leads to broken homes as divorce is common after diagnosis of childhood cancer. There is blaming, shaming and self-blame among spouses. This heightens families' insecurity and safety [2] [24].

\subsection{Family Caregivers' Stressful Experience}

The findings from the study suggest that the participants were overwhelmed by the constraints imposed on them by the demanding caregiving roles provided to the child. Indicators for increased caregiver stress, as observed in this study, were suggestive of a higher likelihood of negative experience that may potentially result in decrease quality of care rendered to the child and decreased quality of life of the parent.

One major concern observed in the study was parental anxiety regarding the child's illness. Seven of the parents expressed anxiety towards the outcome for their child's illness. All participant's verbalised their concerns about the quality of life that their child will have in the future as well as the essence of the treatment as the children experience frequent relapse and hospitalizations resulting in sleepless nights for the parent. Nair and colleagues (2017) observed in their study that cancer diagnoses and treatment in a child is tagged with negative emotions such as anxiety, uncertainty and constant thought on the outcome for the child. This is evident as most families turn to crush down from feeling safe and in control of their life to living with vulnerability and uncertainty [25]. Scholars have identified anxiety, depression and hopelessness as some signs of poor mental health observed among family care givers. The diagnosis of cancer in children imposes excessive amount of stress and anxiety on the family, predominantly parents, affecting their mental health [26].

Closely linked to parental anxiety is altered sleep pattern. All participants had experienced altered sleep due to the child's illness. Most participants shared that their sleeplessness were associated with caring for the child and constant thinking of their current situation. Two participants whose children were on admission had more altered sleep as compared to the rest. These they attributed to fear of the child dying, long duration of treatment and change in environment from their own domicile. Some studies identified sleep disorders to affect parents as they care for their children in the hospital. Lack of sleep makes it hard for par- 
ents to be attuned to the child and provide them with the needed care and positive parenting they need [27].

All parents were directly involved in the care of their sick child and provided information on the demanding nature of their caregiving roles. Care needs provided by parents aside their usual parental duties included sending the child to laboratory or taking scans; holding the child during procedures; administration of their treatment at home; donating blood; home schooling since their conditions will not permit the children go to school; carrying the child to other departments for treatment and investigations; being their only friend since they cannot play with other children and using all mean to provide for them. These experiences shared are in agreement to those reported in other literatures [1] [15]. Beside the personal adjustment made in their lifestyle, their caregiving experience limits or stops any socioeconomic activities which aggravates their financial challenges. All participants had experienced alteration in their quality of life due to the massive changes in lifestyle following the onset of caring for their sick children. These changes were largely negative affecting their psychosocial wellbeing as financial constraints, stigma, constant worrying, altered sleep, fear of the child dying and anxiety denied them of the pleasure in their day to day life. These psychosocial challenges have been widely reported by many studies [2] [3] [23] [28].

There are reports of stigma associated with paediatric cancers. This was experienced by five parents. It is perceived as a curse with associated negative societal perceptions. It became evident that children with obvious physical changes such as abdominal swelling, severe wasting, severe tumour growth, protrusion and hair loose had some discriminatory experiences. These parents felt worried and embarrassed by the stares and comment from other people. In an Egyptian study, parents feared for other members in their community to identify the condition of the child as it is assumed to be a curse disease and can be transfer to others. This was a contrast to this study as other members of the community knew the children were being treated for cancer and parent did not associate the disease to curse.

\subsection{Family Caregivers' Coping/Support Experience}

In the study, financial, spiritual/religious, psychosocial and health workers' support were the main means identified to assist parents during these challenging times. This is affirmed by other studies in Ghana where, financial, spiritual and psychosocial support from the community help parents to cope better during cancer treatment [28] [29] [30].

It was worthy to note that all parents were eager to find cure willingly for their children. This zeal took parents and children to various healing centers before finally seeking orthodox treatment. The mothers' reported that they had first consulted traditional healers before seeking medical intervention in the hospital, due to influence from their traditional belief systems. [23] in their study also observed that traditional African beliefs influences mother's decision in treatment 
options for cancer treatment [24].

Spirituality has been identified as an important resource for coping in relation to family caregivers during chronic illness [31]. In the study, it was evident that spiritual faith increased significantly for all parents during diagnosis and treatment of the child. Spiritual belief cushions parents from their stress of caring for the child and help them generate their own understanding about the illness. However, all participants had some doubt intermittently about their faith as they continually see their child suffer from the illness, side effects of treatment and frequent relapse. Spiritual or religious orientation influences one's feelings about the meaning of life, coping, justice, fairness in life, guilt, altruism and attitude towards medical care.

Social commitment and support parents received from religious bodies also emerged. Eight parents had received social support in the form of money, blood donations, clothing, food and prayers from their churches. These supports gave parents the hope and assurance that other members of their society cared about their wellbeing. The belief in the supreme power of God gave these parents the hope of cure. This coping strategy should be exploited by health care providers to enhance parents coping. This can best be achieved when parents are freely allowed to exercise their faith in an appropriate manner to help them cope with the treatment of the child regardless of the clinicians' belief. Other studies affirmed that religion, spirituality or life philosophy played diverse and important roles in the lives of most parents as it help them to cope [3] [16].

Closely linked to religious support is the appreciation and inner satisfactions gained from social benevolent groups. All participants had benefited from sponsorship provided by individuals, NGO or social support groups. The support these parents gain ranges from food items, money, toys, education of the children while in the hospital to adoption of a hostel to accommodate the parent/child during treatment. It has greatly declined the financial burden of parents and had given them great assurance that their children will receive the needed treatment. The involvement of benefactors in the soliciting of funds and provision of some logistics to cancer patient has greatly reduced some financial burden and allied to anxiety of parents to some extent [32].

Health workers' relationships are the bedrock of patient and parents care. Their interactions with the parents help them acquire in-depth knowledge of their child's condition and also facilitated the parental caregiving role to their sick children. Parents reported that health workers are one of their greatest support and they depend on them to cope. The friendship, attentiveness, education and financial support are some of the means parents cope through health workers. These observations are well documented [33]. Worthy of note, in this study, all parents were knowledgeable about the varied components of child's treatment and care, including identification and management of the illness, treatment plans and outcomes. This positive experience ensured parents had optimum knowledge on the condition of their children. With regards to the nutritional component, many parents were satisfied that they had been counseled on 
the recommended foods to support the recovery and suppress the growth of cancer cells in their children. They endeavor to abide by this counsel. Parents who are unable to provide for the nutritional needs of the children felt bad and sad about the situation as they knew this could affect the child's recovery or the child's ability to remain stable. With regard to side effect of chemotherapy and other treatment, all the parents were aware of the side effects of their children's treatment. Parents were made aware of first aids to give to the child prior to brining the child to the hospital if the need be. They were also aware of danger signs that must be reported immediately to the hospital. They acknowledge that this knowledge was pivotal in their decision to maintain their children in the cancer treatment program. Increased knowledge of parents about all aspects of their child's care has been reported in the scientific literatures and has been attributed to factors such as parental desire to learn more about the child's illness, higher level of education of family caregivers especially women and interactive relations with health care providers [25].

The interactions and teaching from health workers are what have helped these parents make informed choices about the child's treatment through empowerment and family centered care. Parental involvement in their child's care helps them to gain in-depth understanding of the treatment and adequate handling of their children. This aligns with these studies that reported that counseling provided to parents by health workers at the commencement of treatment serves as a guiding light through the cumbersome trajectory of cancer treatment [25] [34]. Parents reported that health workers are one of their greatest support and they depend on them to cope. Health workers' attitude, practices and support in paediatric cancer management is integral to adherence and maintaining the patient in their treatment programs.

The study authenticates that parents have both positive and negative psychosocial experiences at the Paediatric Oncology Unit of KBTH. These results are anticipated to inform proactive interventions that would facilitate the care provided to parents as their children undergo cancer therapy. There is the need for government and hospital administration to institute a trust fund to assist parents in the care and treatment of their children. Enhancing parents' education and public awareness of childhood cancers is essential to promote early identification and better treatment outcomes for the child and family. Health workers should utilize positive interactions, spirituality and family support to provide a holistic family centered and strength-based care to the parent and child.

\section{Acknowledgements}

I am grateful to all participants and staff of Korle-Bu teaching hospital paediatric oncology unit.

\section{Conflicts of Interest}

The author declares that there is no conflict of interest. 


\section{References}

[1] Hoven, E., Gronvist, H., Poder, U., Essen, L.V. and Norberg A.L. (2017) Impact of a Child's Cancer Disease on Parents' Everyday Life: A Longitudinal Study from Sweden. Acta Ongologica, 56, 93-100. https://doi.org/10.1080/0284186X.2016.1250945

[2] Hosod, T. (2014) The Impact of Childhood Cancer on Family Function: A Review. Graduate Student Journal of Psychology, 15, 18-30.

[3] Jones, B. (2012) The Challenges of Quality of Life for Family Caregivers in Paediatric Cancer Care. Seminars in Oncology Nursing, 28, 213-220. https://doi.org/10.1016/j.soncn.2012.09.003

[4] Wangmo, T., Ruhe, K.M., Badarau, D.O., Kuhne, T., Niggli, F. and Elger, B.S. (2016) Parents and Patients Experiences with Paediatric Oncology Care in Switzerland-Satisfaction and Some Huddles. Swiss Medical Weekly, 146, Article No. w14309. https://doi.org/10.4414/smw.2016.14309

[5] Craft, A. (2000) Childhood Cancer-Mainly Curable so Where Next? Acta Paediatrics, 89, 386-392. https://doi.org/10.1111/j.1651-2227.2000.tb00075.x

[6] Day, S., Challinor, J., Abramovitz, L., Hollis, R., Hanaratri, Y. and Punjwani, R. (2015) Paediatric Oncology Nursing Care in Low- and Middle-Income Countries: A Need for Baseline Standards. Cancer Control, 28, 111-116.

[7] Kohlsdorf, M. and Costa, A.L.J. (2012) Psychosocial Impact of Paediatric Cancer on Parents: A Literature Review. Aspectos Psicossociais do Cancer, 22, 119-129. https://doi.org/10.1590/S0103-863X2012000100014

[8] America Cancer Society (2016) Key Statistics for Childhood Cancers. The American Cancer Society and Editorial Content Team, New York City.

[9] Paintsil, V., Blay, S.N., Osei-Akoto, A., Osei-Tutu, L. and Hammond, C. (2015) Pattern of Childhood Cancers Presenting to the Paediatric Cancer Unit of a Tertiary Hospital in Kumasi, Ghana. Journal of Cancer Prevention and Current Research, 3, Article No. 83. https://doi.org/10.15406/jcpcr.2015.03.00083

[10] Renner, L., Shah, S., Bhakta, N., Denburg, A., Horton, S. and Gupta, S. (2018) Evidence from Ghana Indicate That Childhood Cancer Treatment in Sub-Saharan Africa Is Very Cost Effective: A Report from the Childhood Cancer 2030. Journal of Global Oncology, 4, 1-9. https://doi.org/10.1200/JGO.17.00243

[11] Segbefia, C.I., Renner, L.A., Dei-Adomakoh, Y. and Welbeck, J. (2013) Changing Pattern in Paediatric Oncology in Korle-Bu Teaching Hospital, Accra, Ghana. Postgraduate Medical Journal of Ghana, 2, 65-67.

[12] Osei-Tutu, L. (2017) Statement from the Ghana Childhood Cancer Network in Collaboration with the Paediatric Society of Ghana for the Childhood Cancer Awareness Month of September 2017. African Journal of Current Medical Research, 1.

[13] Limburg, H., Shaw, A.K. and McBride, M.L. (2008) Impact of Childhood Cancer on Parental Employment and Source of Income: A Canadian Pilot Study. Paediatric Blood and Cancer, 51, 93-98. https://doi.org/10.1002/pbc.21448

[14] Kerr, L.M., Harrison, M.B., Medves, J. and Tranmer, J. (2004) Supportive Care Need of Parents of Children with Cancer: Transition from Diagnosis to Treatment. Oncology Nursing Forum, 31, E116-E126. https://doi.org/10.1188/04.ONF.E116-E126

[15] James, K., Keegan-Wells, D., Hinds, P.S. and Kelly, K.P. (2002) The Care of a Child with Cancer: Parents' Perception of Care Giving Demands. Journal of Paediatric Oncology Nursing, 19, 212-228. https://doi.org/10.1177/104345420201900606

[16] Hexem, K.R., Mollen, C.J., Carroll, K., Lanctot, D.A. and Feudtner, C. (2011) How Parents of Children Recovering Pediatric Palliative Care Use Religion, Spirituality 
or Life Philosophy in Tough Times. Journal of Palliative Medicine, 4, 39-44. https://doi.org/10.1089/jpm.2010.0256

[17] Wiener, L., Viola, A.,Kearney, J., Mullins, L.L., Sherman-Bien S., Zadeh, S., Farkas-Patenaude, A., Poa, M. and Lone Parents Support Group (2016) Impact of Caregiving for a Child with Cancer on Parental Health Behaviours, Relationship Quality and Spiritual Faith: Do Lone Parents Fare Worse? Journal of Paediatric Oncology Nursing, 33, 378-386. https://doi.org/10.1177/1043454215616610

[18] The Royal Children's Hospital Children's Cancer Centre Psycho-Oncology Team (2012) Emotional Care and Childhood Cancer. A Guide for Health Professionals. Victoria Paediatric Integrated Cancer Service, Melbourne, 1-17.

[19] Hatch, M. and Posel, D. (2018) Who Cares for Children? A Quantitative Study of Childcare in South Africa. Journal Development Southern Africa, 35, 276-282.

[20] Cristina Stefan, D. (2015) Patterns of Distribution of Childhood Cancer in Africa. Journal of Tropical Paediatrics, 61, 165-173. https://doi.org/10.1093/tropej/fmv005

[21] Brand, S., Wolfe, J. and Samsel, C. (2017) Impact of Cancer and Its Treatment on the Growth and Development of Pediatric Patients. Current Pediatric Review, 13, 24-33. https://doi.org/10.2174/1573396313666161116094916

[22] O'Brien, S., Nadel, S., Almossawi, O. and Inwald, D.P. (2017) The Impact of Chronic Health Condition on Length of Stay and Mortality in a General PICU. Paediatric Critical Care Medicine, 18, 1-7. https://doi.org/10.1097/PCC.0000000000000976

[23] Clarke, S., Mitchill, W. and Sloper, P. (2004) Care and Support Needs of Children and Young People with Cancer and Leukaemia and Their Families. University of New York, New York.

[24] Naidoo, D. and Gurayah, T. (2016) Having a Child with Cancer: African Mothers' Perspective. South African Journal of Occupational Therapy, 46, 49-54. https://doi.org/10.17159/2310-3833/2016/v46n3a9

[25] Nair, M., Paul, L.T., Latha, P.T. and Parukkutty, K. (2017) Parents' Knowledge and Attitude Regarding Their Child's Cancer and Effectiveness of Initial Disease Counseling in Paediatric Oncology Patients. Indian Journal of Palliative Care, 23, 393-398. https://doi.org/10.4103/IJPC.IJPC_83_17

[26] Nasab, A.A. and Foroghi, M. (2016) Mental Health Status of the Parents of Pediatric Cancer Patients. Biomedical \& Pharmacology Journal, 9, 1107-1110. https://doi.org/10.13005/bpj/1056

[27] McCann, D. (2008) Sleep Deprivation Is an Additional Stress for Parents Staying in the Hospital. Journal of Specialist in Paediatric Nursing, 13, 111-122. https://doi.org/10.1111/j.1744-6155.2008.00142.x

[28] Weiten, W. and Lloyd, M.A. (2008) Psychology Applied to Modern Life. 9th Edition, Wadsworth Cengage Learning, Boston.

[29] Carver, C.S. and Connor-Smith, J. (2010) Personality and Coping. Annual Review of Psychology, 61, 679-704. https://doi.org/10.1146/annurev.psych.093008.100352

[30] Renner, L.A. and McGill, D. (2016) Exploring Factors Influencing Health Seeking Decision and Retention in Childhood Cancer treatment Programmes: Perspective of Ghanaian Parents. Ghana Medical Journal, 50, 149-156. https://doi.org/10.4314/gmj.v50i3.6

[31] Roger, K.S. (2018) Religion, Spirituality and Chronic Illness: A Scope Review and Implication for Health Care Practitioners. Journal of Religion and Spirituality in Social Work: Social Thought, 37, 24-44.

https://doi.org/10.1080/15426432.2017.1386151 
[32] Hushie, M. (2016) Public-Non-Governmental Organization Partnership for Health: An Exploratory Study with Case Study from Recent Ghanaian Experience. BMC Public Health, 16, Article No. 963. https://doi.org/10.1186/s12889-016-3636-2

[33] Walton, M. (2011) Supporting Family Caregivers: Communicating with Family Caregivers. American Journal of Nursing, 111, 47-53. https://doi.org/10.1097/01.NAJ.0000408186.67511.b9

[34] Rosenberg, A.R., Dussel, V. and Kang, T. (2013) Psychological Distress in Parents of Children with Advance Cancer, JAMA Paediatrics, 167, 537-543.

https://doi.org/10.1001/jamapediatrics.2013.628

\section{Abbreviations}

CHD: Child Health Department

IRB: Institutional Review Board

KBTH: Korle-Bu Teaching Hospital

NGO: Non-Governmental Organization

NHIS: Nation Health Insurance Scheme

STC: Scientific and Technical Committee 